\title{
MJN AN EVALUATION OF THE FAMILY PLANNING COUNSELLING PROGRAM UTILIZING OBJECTIVE BASED MODEL
}

\author{
Jonaid M. Sadang ${ }^{1 *}$, Naima D. Mala ${ }^{1}$, Jezyl Cutamora² \\ ${ }^{1}$ College Secretary, College of Health Sciences Mindanao State University, Philippines \\ ${ }^{2}$ Cebu Normal University, Cebu City, Philippines
}

*Corresponding Author's Email: jonaidsadang@yahoo.com

\begin{abstract}
This study primarily aimed to evaluate the status of modern Family Planning Program (mCPR) in the Province of Lanao del Sur based on national objective to increase modern Contraceptive Prevalence Rate (mCPR) among all women from $24.9 \%$ in 2017 to $30 \%$ by 2022 . More specifically, it attempts to answer the following research questions: how many numbers of family planning counselling were given to the clients from 20112018; what is the percentage status of modern Contraceptive Prevalence Rate (mCPR) from 2011-2018; and if family planning counselling given can significantly predict modern Contraceptive Prevalence Rate from 20112018. Descriptive and evaluative research design using quantitative approach in the interpretation of data was employed in this study. Data that was used in this study was taken from the annual reports of Integrated Provincial Health Office in Lanao del Sur, Philippines from 2010 - 2018 through data mining process, after taking the formal consent from the appropriate responsible authority. The data was then subjected to multiple linear regression analysis through SPSS software to test the research hypothesis. Results revealed that family planning counselling given to the clients was statistically significant in predicting the modern Contraceptive Prevalence Rate from 2011-2018 in Lanao del Sur, Philippines. Hence, strengthening of the family planning counselling program should be one of the top priorities of family planning program in the Bangsamoro Autonomous Region in Muslim Mindanao (BARMM) provinces to increase the coverage number of acceptors especially on Modern Contraceptive Methods of Family Planning.
\end{abstract}

Keywords: Family Planning, Counselling, Modern Contraceptive Methods, Descriptive-Evaluative

\section{INTRODUCTION}

Family planning programs are the key index of comprehensive sexual and reproductive health. They provide essential and often life-saving services to women, their families, and the community. By enabling women to delay pregnancy, avoid childbearing, or space births, prevent unwanted teenage pregnancies, reducing infant mortality, help in preventing HIV/AIDS, and even effective in slowing population growth. Family planning programs are not only fundamental to women's health, they also allow women and families to better manage household and natural resources, secure education for all family members, and address each family member's healthcare needs.

However, recent data shows that an estimated 225 million women globally have an unmet need for family planning. In other words, they do not wish to have a child at this time, yet are not using effective contraception. This lack of access to family planning methods is a contributor to the preventable deaths of 303,000 women annually due to pregnancy related causes. In fact, data shows that around 214 million women in the reproductive age in developing countries who want to avoid pregnancy are not using a modern contraceptive method (WHO, 2018).

According to the report of UNDESA on the trends in contraception worldwide 2015, the unmet need for contraception remains too high. This inequity is fuelled by both a growing population, and a shortage of family planning services. In Africa, $24.2 \%$ of women of reproductive age have an unmet need for modern contraception. In Asia, and Latin America and the Caribbean-regions with relatively high contraceptive prevalence - the levels of unmet need are $10.2 \%$ and $10.7 \%$, respectively (WHO, 2018). 
In the Philippines, family planning program started around 1970s, when we had a similar population to Thailand of around 40 million. But now our population is roughly 95 million, while Thailand only has 65 million (Asian Scientist, 2012). However, for years, family planning campaigns are seriously lacking in the country, when compared to its neighbouring countries in South-east Asia. In fact, statistics shows that only 38\% of married women rely on modern contraceptives, while almost half are not using any contraceptive method. As a result, according to the World Health Organization more than one in four births is unwanted. Since 1990, total fertility has reduced from four to three births per woman. Only sparsely populated Laos and the relatively new nation of Timor-Leste have higher fertility, while only Timor-Leste has lower contraceptive use (Mirkin, 2019).

In addition, documented reports from PSA (2001), shows that the contraceptive prevalence rate (CPR) or the proportion of married women 15-49 years reporting current use of contraceptives drops to $47 \%$ in 2000 from the $49.3 \%$ recorded in 1999 . This is primarily caused by the decrease in the use of traditional methods $(16.9 \%$ to $14.7 \%)$, particularly withdrawal $(6.7 \%$ to $4.8 \%)$. Meanwhile, the prevalence rate of modern methods levelled off in the last two years (32.4\% in 1999 and $32.3 \%$ in 2000). Family Planning Survey (FPS) results from 1995 to 2000 reveal a decline in the CPR, from $50.7 \%$ in 1995 to $47 \%$ in 2000 . The same rate of contraceptive use was recorded in the 1997 FPS and in the 1998 National Demographic and Health Survey (NDHS). The 1999 FPS estimate for the CPR $(49.3 \%)$ was a marked improvement, particularly the prevalence rate of modern methods (from $28.2 \%$ in 1998 to $32.4 \%$ in 1999).

Thus, to address these issues, in 2012, the Republic Act No. 10354 on Responsible Parenthood and Reproductive Health Law was enacted under President Noynoy Aquino. This law provides the access to a full range of methods, facilities, services and supplies that contribute to reproductive health and well-being by addressing reproductive health-related problems. It also includes sexual health, the purpose of which is the enhancement of life and personal relations.

In addition, President Rodrigo Duterte signed an executive order providing funds and support for modern family planning, in a bid to make modern family planning available to the poor by 2018. This Order aims to intensify and accelerate the implementation of critical actions necessary to attain and sustain 'zero unmet need for modern family planning' for all poor households by
2018, reads Executive Order No. 12, signed by Duterte on January 9 and released on Wednesday. Among the strategies outlined in the four-page document is to do a comprehensive review of couples and individuals in need of family planning services (Cabato, 2017).

On a slight brighter side, the use of modern family planning methods increased in most regions. However, in the Autonomous Region in Muslim Mindanao which includes the Province of Lanao del Sur, despite a 2.9\%point increase in the prevalence rate for modern methods, the region still holds the lowest rate among the regions at only $10.5 \%$ (PSA, 2003). In fact, the recent consolidated report on the implementation of the Reproductive Health Law revealed the use of modern family planning methods in the country at $43.8 \%$ in 2015 , an increase from $41.14 \%$ in 2014 . It has been steadily increasing over the years, from $33.4 \%$ in $2003,34 \%$ in 2008 , and $37.6 \%$ in 2013. Unfortunately, the growth in national modern contraceptive prevalence rate (mCPR) was not able to catch up with the increase in eligible population, since the eligible population of women in reproductive age grew by $1.9 \%$ every year, while mCPR only increased by $1.78 \%$ (Geronimo, 2016).

It is important that family planning policies are widely available and easily accessible through trained health providers to anyone who is sexually active, including adolescents. Healthcare providers should be trained to provide locally available and culturally acceptable contraceptive methods including counselling of the different family planning methods. Often, women who are living in geographically isolated areas with poor health services tend to have fewer education and economic opportunities, which can limit their access to family planning. Hence, this study primarily aims to evaluate the status of modern Family Planning Program (mCPR) in the Province of Lanao del Sur from 2011-2018 based on national objective to increase modern Contraceptive Prevalence Rate (mCPR) among all women from $24.9 \%$ in 2017 to $30 \%$ by 2022 . The results of the assessment will become the basis for development of appropriate and effective strategies in strengthening family planning programs in geographically underserved and poor performing areas including the provinces of Bangsamoro Autonomous Region in Muslim Mindanao.

\section{Problem Statement}

This research study primarily aims to evaluate the status of modern Family Planning Program (mCPR) in the Province of Lanao del Sur from 2011-2018 based on national objective to increase modern Contraceptive Prevalence Rate (mCPR) among women from $24.9 \%$ in 
2017 to $30 \%$ by 2022 .

\section{Framework}

Figure 1 presents the conceptual framework of the study. The assessment included the description of the family planning indicators in terms of family planning counselling given and modern Contraceptive Prevalence Rate (mCPR). Family Planning Program (FP) is one of the umbrella programs of the Department of Health which is committed to provide responsive policy direction and ensure access of Filipinos to medically safe, legal, non-abortifacient, effective, and culturally acceptable modern family planning (FP) methods. It was designed in order to have the desired number of children by using safe and effective modern contraceptive methods. Proper birth spacing i.e. having children 3 to 5 years apart, which is best for the health of the mother, her child, and the family (DOH, 2019).

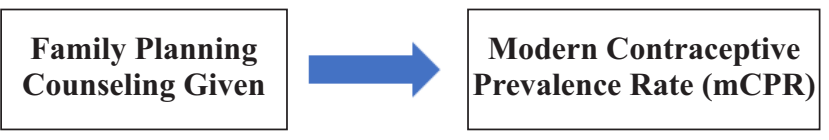

Figure 1: An Evaluation of the Family Planning Counselling Program Utilizing Objective Model

\section{LITERATURE REVIEW}

One out of four currently married women 15-49 years old practicing family planning intends to stop doing so. Also, among the non-users, one in four intends to use a method at any time in the future, according to the 2005 Family Planning Survey (Philippine Statistics Authority, 2006).

A study in Pakistan on the integrated approach to changing women's family planning behaviour (Najmi et al., 2018), results showed that contraceptive prevalence rate increased by $10.7 \%$, from $42.3 \%$ at baseline to $53.0 \%$ mid-intervention, with an increase in use of modern contraceptive methods of $9.2 \%$. A significant association was found between door-to-door counselling and the use of contraceptive methods (OR 3.4, 95\%; CL 2.9-4.1) and access to public and private facilities for modern contraceptives (OR 2.4, 95\%; CL 2.0-3.0).

Important barriers to the utilisation of Post-Partum Family Planning in Liberia were being within early post-partum period, lack of access and awareness of Post-Partum. Family Planning including myths and misconception. Therefore, health communication targeting mothers for PPFP at every contact with maternal and childcare services should be encouraged (Kaydor et al., 2018).
In addition, a study conducted in Nepal concluded that education plays a vital role in the acceptance of family planning. As couples who have higher education level tend to have higher income and they have lesser number of children. They are more receptive towards counseling and agree upon the various methods of family planning. The easy accessibility to the various media like radio, television tends to make people aware of various methods of family planning (Shrestha et al., 2014).

However, it is interesting to note that a study conducted in North India among Muslim women showed that majority (87\%) had knowledge about family planning, but only $47 \%$ of the married women are currently using some kind of family planning method (Shumayla \& Kapoor, 2016).

Another study conducted by Mufdlilah et al., (2017), results shows that respondents have some reasons of drop out from family planning such as side effect, more children motivation, contraceptive method change, discomfort/inconvenience, expired date, and health problems. This is in line with a study by Musdalifah (2013) and Handayani et al., (2012), where side effect becomes the problem experienced by most of family planning drops out which is possibly caused by the lack of counselling, information, and education.

A study assessing the knowledge, attitude and practice of family planning among women living in the Mbouda health district, Cameroon (Nansseu et al., 2015), with 101 women were enrolled with age ranging from $18-58$ years of age with a mean of $31.7 \pm 8.8$ years. Results showed that the main reasons precluding women from practicing contraception were lack of knowledge $(31.4 \%)$, ignorance $(31.4 \%)$ and unbearable side effects $(8.6 \%)$.

\section{METHODOLOGY}

\section{Design}

This study primarily used a descriptive and evaluative research design using quantitative approach in the interpretation of data. Descriptive studies objectively portray the characteristics of persons, situations, or groups, and/or frequency with which certain phenomena occur. While, an evaluative research involves investigating how well a program, practice, or policy is working. On the other hand, inferential method is based on the laws of probability to provide a means for drawing conclusions about a population, given a data from the sample. This was used to investigate and determine whether and to what degree, a relationship exists between the independent and dependents 
quantitative variables (Polit \& Beck, 2008).

\section{Locale}

The data used in this study were taken from the annual reports of Integrated Provincial Health Office in Lanao del Sur, Philippines from 2010-2018 through data mining process, after taking the formal consent from the appropriate responsible authority. The province is composed of 39 municipalities and is divided into six health districts namely; Malabayabao, Wao, Tamparan, Balindong, Unayan and Malabang districts, and each district is composed of different municipalities. Integrated Provincial Health Office being the main health government agency in the province is mandated for the formulation, planning, implementation and coordination of policies and programs in the field of health including family planning programs.

\section{Data Gathering Procedure}

This study utilized data mining process in order to gather necessary information through extracting potentially useful information from the data sets available in the Province of Lanao del Sur, Philippines. Data mining involves use of techniques to find underlying structures and relationships in a large database. Data mining is becoming more and more vital because of the variety of techniques such as neural networks, knowledge discovery, data visualization, fuzzy query analysis and case-based reasoning used in applications and services that can be built using the same (Girija et al., 2006). Data which was utilized in this study was taken from the annual reports of the Province of Lanao del Sur from 2011-2018, and was validated by the provincial coordinator prior to the submission in the regional office of Bangsamoro Autonomous Region in Muslim Mindanao-Ministry of Health. The researcher submitted a letter of permission and approval to gather the necessary data to the immediate organizational head. Research ethics was primarily observed and maintained throughout the duration of conducting the study. Data which was collected remained confidential to the maximum degree possible.

\section{Statistical Treatment of Data}

The collected data was subjected to multiple linear regression analysis through SPSS software to test the research hypothesis (Polit \& Beck, 2008). It is a statistical technique that uses several explanatory variables to predict the outcome of a response variable. The goal of multiple linear regressions (MLR) is to model the linear relationship between the explanatory (independent) variables and response (dependent) variable. It is calculated using the formula, $y i=\beta 0+$ $\beta 1 x i 1+\beta 2 x i 2+\ldots+\beta p x i p+\epsilon$ (Kenton, 2019). The findings will then become the basis for analysis, interpretation of results, drawing conclusions, implications, and recommendations.

\section{RESULTS AND DISCUSSION}

The flow of the presentation, discussion and analysis of data follows the pattern of the study's statements of the problem and is carried out in four tables.

Table 1: Descriptive Statistics for Family Planning Counseling Given from 2011 - 2018

\begin{tabular}{|c|c|c|c|}
\hline Variable & Mean & Std. Deviation & Median \\
\hline $\begin{array}{c}\text { Family Planning } \\
\text { Counselling Given from } \\
\text { 2011-2018 }\end{array}$ & 42484.0000 & 17128.10466 & 47761.5000 \\
\hline
\end{tabular}

The data shows (table 1) that family planning counseling program on the average reached almost half of the Married Women of Reproductive Age with a total population ranging from 107, 231-114,850 from 2011 to 2018 respectively with a grand mean of 42484.0000 $(\mathrm{SD}=17128.10466)$.

An individual's belief about family planning practices are shaped by the culture in which she is raised. Engaging women and their partners in culturallyresponsive family planning and contraception counselling is one essential element of preconception care, a primary care concept designed to reduce infant mortality and its associated racial/ethnic disparities. The common known benefits of family planning among mothers include but not limited to; and that enables her to regain her health after delivery, gives enough time and opportunity to love and provide attention to her husband and children, gives more time for her family and own personal advancement, and when suffering from an illness, gives enough time for treatment and recovery. In 2008, use of contraceptive methods prevented over 250,000 maternal deaths by reducing unintended pregnancies. This is equivalent to $40 \%$ of the 355,000 maternal deaths for the year. The number of maternal deaths would decrease by a further $30 \%$ in developing countries, if all women who wish to avoid pregnancy use an effective contraceptive method (Cleland et al., 2012).

A cross-sectional study conducted in Irbid, Jordan among 200 women attending two private clinics affiliated with the Jordanian Association for Family Planning and Protection (JAFPP) and six governmental clinics were invited to participate in the study. Counselling sessions 
were attended by an independent observer and evaluated with regards to their compliance with the standard Greet, Ask, Tell, Help, Explain, Return (GATHER) framework. Results of 198 women (response rate: 99.0\%), including 80 women (40.4\%) from JAFPP clinics and 118 (59.6\%) from governmental clinics. In total, $42.9 \%$ of the counselling sessions were deemed adequate, with providers applying $80 \%$ or more of the GATHER framework, while $26.8 \%$ of the sessions were deemed semi-adequate and $30.3 \%$ were considered inadequate. Counselling services provided in the governmental clinics were significantly less adequate than those provided in JAFPP clinics (Okour et al., 2018).

A study on perceptions of and barriers to family planning services found out that there were intergenerational and cultural gaps in the acceptability of family planning, and in some community's family planning use was greatly restricted by gender roles and religious objections. Men strongly influenced family planning choices in many households but were largely unreached due to the lack of educational programs. Respondents were aware of many modern methods but often lacked deeper knowledge and held misconceptions regarding long-term fertility risks posed by some hormonal methods. Acute physical side effects also dissuaded use (Dansereau et al., 2017).

In addition, a descriptive, cross-sectional, exploratory study conducted in Egypt found that 46 of the 77-family planning non-users aged between 21-30 years reported cognitive barriers (59.7\%) and 33 reported cultural barriers (42.8\%). Cognitive as used in this study refers to participants who did not hear or see any advertisement about FP in last 6 months/did not participate in an educational session about FP during last 6 months/think that FP is good behavior in a woman's life (Eltomy et al., 2013).

Table 2: Descriptive Statistics for modern Contraceptive Prevalence Rate from 2011 - 2018

\begin{tabular}{|c|c|c|c|}
\hline Variable & Mean & Std. Deviation & Median \\
\hline $\begin{array}{c}\text { Family Planning } \\
\text { Counselling Given from } \\
\text { 2011-2018 }\end{array}$ & 19.1188 & 4.36726 & 19.2000 \\
\hline
\end{tabular}

The level of current use of modern family planning is the most widely used indicator for evaluating the success of national family planning programmes. Table 2 shows that on the average the status percentage of modern Contraceptive Prevalence Rate in the province of Lanao del Sur is $\mathrm{M}=19.1188$ ( $\mathrm{SD}=4.36726)$. This data would imply that the status of modern Contraceptive Prevalence Rate in the province was quiet far from the $24.9 \%$ national mCPR of the country for the year 2017. This could further mean that it would take a lot of effort for the family planning program in the province to reach the national target to increase the mCPR in 2017 into $30 \%$ by 2022 .

Recently the prevalence of traditional methods has increased in Jordan. In Jordan, the overall contraceptive prevalence rate has increased markedly over the past 2 decades, from $40 \%$ in 1990 to $61 \%$ in 2012 . However, the reliance on modern methods has levelled off at $42 \%$ in the last decade, which is not in line with Jordan's family planning programme objective of achieving $80 \%$ of currently married women (15-49 years) using modern contraceptives. Among 10,801 currently married women aged 15-49 years surveyed, 38.8\% were not using any contraceptive method, $18.9 \%$ used traditional methods, and $42.3 \%$ relied on modern contraceptive methods (Almalik et al., 2018).

In Sub- Saharan Africa including Ghana continues to portray low uptake of modern contraceptives. Their findings indicate that contraceptives use is the cause of the high fertility rates in Sub-Saharan African countries resulting in early childbearing, high infant mortality and many other negative effects on the socio-economic situation in a country (Creanga et al., 2011). According to the GDHS 2014, the use of modern contraceptive is low among women aged 15-19 (19\%) and women age 45-49 (18\%) (Ghana Statistical Service, 2009).

On the other hand, results of the 2011 Family Health Survey (FHS) which updated the findings from the 2006 Family Planning Survey (FPS) and 2008 National Demographic and Health Survey (NDHS) show an almost stagnant trend in the use of contraception among currently married women of reproductive age (CMWRA), which is 15 to 49 years of age in the Philippines. The practice of family planning among CMWRA has declined from 50.6 percent in 2006 to 48.9 percent in 2011. Disaggregated by method, the use of traditional or natural family planning decreased, from 14.8 to 12.0 percent, with the exception of the withdrawal method which increased by 0.9 percentage points. Meanwhile, the overall prevalence of modern contraceptives marginally increased, from 35.9 to 36.9 percent, which can be attributed to the increase in the use of pills and injectables. In terms of location, there are slightly less women who use FP methods in rural (48.3\%) than urban (49.6\%) areas. Asked why they are not using FP services, the respondents of the 2011 Family Health Survey point to wanting children, fear of side effects, 
inaccessibility of Family Planning services, infrequent or no sex, and infecundity as the top five reasons (SEPO, 2013). Most of these reasons could definitely be addressed through proper and adequate family planning counselling program.

A recent study on Filipino women who use contraceptives showed that in the past 10 years, one in every three women relied more on traditional contraceptive methods rhythm and withdrawal than modern methods. Though modern birth control methods were the most prevalent across all survey periods, the use of traditional methods accounted for nearly onethird of contraceptive use from 2003 to 2013 (Jadloc, 2017).

\section{Predictor}

The following tables provide the summary results of the statistical treatment of the dependent variable and its predictor. Results were obtained with the use of multiple regressions.

Table 3: Predictor, Family Planning Counselling Given and modern Contraceptive Prevalence Rate from 2011 2018

\begin{tabular}{|l|c|c|c|}
\hline $\begin{array}{l}\text { Independent } \\
\text { Variable }\end{array}$ & Dependent Variable & R Square & Sig. F Change \\
\hline $\begin{array}{l}\text { Family Planning } \\
\text { Counselling Given }\end{array}$ & $\begin{array}{l}\text { modern Contraceptive } \\
\text { Prevalence Rate from }\end{array}$ & 0.857 & 0.001 \\
\hline
\end{tabular}

Predictors: (Constant), family planning counselling given 2011-2018

The Family Planning Counselling is statistically significant in predicting the modern Contraceptive Prevalence Rate from 2011-2018 in Lanao del Sur, Philippines. The implication of these finding would tell us that the information and awareness - raising aspect with respect to Family Planning Program is deemed highly important in improving the status of modern Contraceptive Prevalence Rate in the province.

Currently, approximately 214 million women of reproductive age in low - and middle - income countries want to avoid pregnancy, yet are not using a modern contraceptive method. Additionally, within the next decade, a record number of adolescents in the lowresource regions will enter their reproductive years. In the future, as in the past, family planning (FP) will help save the lives of countless women and children, and will help alleviate poverty, reduce stress on the environment, and ensure that families are better able to feed, provide clothes, and educate their children (Yacobson, 2018).
In South Central and Southeast Asia the use of modern contraception is less than global average; with only $47 \%$ of married women aged 15-49 years use modern contraceptives, although higher proportions want to prevent pregnancy. The $32 \%$ of women, who used a traditional method or no method at all, accounted for $85 \%$ of unintended pregnancies in 2008 (United Nations Population Fund, 2009). The rate of annual abortions in Asia slightly increased from 25.9 million to 27.3 million between 2003 and 2008. About $60-65 \%$ of abortions in South Central Asia, Southeastern Asia and Western Asia were performed unsafely (Guttmacher Institute, 2012).

In addition, Asia in 2008, 17,000 maternal deaths which include $12 \%$ of all maternal mortality rate were reported due to unsafe abortion (World Health Organization, 2011). The recent DHS analytical studies show the modern contraceptive prevalence among married women (15-49) in Asian country varied from $14 \%$ in Azerbaijan, 20\% in Armenia, 22\% in Pakistan, $34 \%$ in Philippines, $35 \%$ in Cambodia, $42 \%$ in Jordan, $48 \%$ in Bangladesh, $49 \%$ in India (Westoff, 2012). The lowest levels of satisfied demand for modern contraception in Asia belong to Armenia and Azerbaijan, at $21 \%$ and $27 \%$, respectively. In Cambodia, Pakistan and the Philippines the levels of satisfied demand are below 50\% (Westoff, 2012).

Contraceptive counselling in the pre and post - natal period may be important for the use of postpartum contraception. Fifty-nine percent of Italians and $63 \%$ of immigrants received contraceptive counselling by natal care services. Women who received counselling are more likely to use effective contraceptives (Italians $\mathrm{OR}=2.55$ 95\% CI 2.06 - 3.14; immigrants OR $=4.0195 \%$ CI 2.40 6.70) (Lauria et al., 2014).

A study in Dominican Republic of Congo on the barriers of modern contraceptive use shows a lack of knowledge contributes to the poor access of participants in the said program. Despite these barriers, many women in the study indicated that they were open to adopting a modern family planning method in the future. These findings imply that programming must address comprehension and decision-making alike in order to trigger positive changes in behaviour and perceptions relating to contraceptive use (Muanda et al., 2017).

Clients usually tend to neither underestimate the effectiveness of the methods nor overestimate the effectiveness of the methods. Sometime misinformed decisions are made by choosing a contraceptive method 
that does not meet their needs. Counselling may need to gently correct these common misperceptions. Good counselling helps clients choose and use family planning methods that suit them. Clients differ, their situations differ, and they need different kinds of help. The best counselling is tailored to the individual client.

In counselling it is not possible or necessary to provide complete information about every method. Clients do, however, benefit from key information, especially about the method that they want. The goal of counselling about method choice is to help the client find a method that she or he can use successfully and with satisfaction. Well-informed clients are more likely to be satisfied with their method and to use it longer. With complete knowledge and understanding of the contraceptive methods, clients are better able to exercise their right to make a truly informed choice. Increased awareness of the importance of family planning program can be achieved through public outreach and improved collaboration between health care providers.

Table 4: Coefficients, Significant Influence Family Planning Counselling Given and modern Contraceptive Prevalence Rate from 2011 - 2018

\begin{tabular}{|c|c|c|c|c|c|c|}
\hline \multirow[b]{2}{*}{$\begin{array}{c}\text { Independent } \\
\text { Variable }\end{array}$} & \multirow[b]{2}{*}{$\begin{array}{c}\text { Dependent } \\
\text { Variable }\end{array}$} & \multicolumn{2}{|c|}{$\begin{array}{c}\text { Unstandardized } \\
\text { Coefficients }\end{array}$} & \multirow{2}{*}{\begin{tabular}{|c}
$\begin{array}{c}\text { Standardized } \\
\text { Coefficients }\end{array}$ \\
Beta
\end{tabular}} & \multirow{2}{*}{$t$} & \multirow{2}{*}{ Significance } \\
\hline & & B & $\begin{array}{c}\text { Std. } \\
\text { Error }\end{array}$ & & & \\
\hline $\begin{array}{c}\text { Family } \\
\text { Planning }\end{array}$ & $\begin{array}{c}\text { modern } \\
\text { Contraceptive }\end{array}$ & & & & & \\
\hline $\begin{array}{l}\text { Counselling } \\
\text { Given from } \\
\text { 2011-2018 }\end{array}$ & $\begin{array}{c}\text { Prevalence } \\
\text { Rate from } \\
\mathbf{2 0 1 1 - 2 0 1 8}\end{array}$ & 0.000 & 0.000 & 0.926 & 6.008 & 0.001 \\
\hline
\end{tabular}

The Philippines has a contraceptive prevalence rate of $55 \%$, based on the 2013 Philippines National Demographic and Health Survey (NDHS). Most contraceptive users rely on modern methods, but over the past 10 years traditional method has been used by about a third of all contraceptive users in the country. Results show that among users of traditional rather than modern contraceptive methods, women in 2003 and 2008 were more likely to use rhythm over modern contraceptive methods compared with women in 2013, while withdrawal rather than modern contraceptive methods were preferred more by women in 2013 than in 2003 (USAID, 2017).

The promotion of family planning and contraceptive use have taken different directions on the implementation of the population program. The enactment of the Population Act (Republic Act 6365) in 1971 formally established the official family planning program of the country under the Commission on Population. However, beginning in the 1980s the family planning program was transferred to the Department of Health and became one of the components of the public health program. During the administration of President Gloria Macapagal Arroyo (2001-2010), there was a strong focus on natural family planning (NFP) methods endorsed by the Catholic Church. In general, the shifts and turns in the direction of the family planning program are attributed to the position of the incumbent President on artificial contraception, the strong influence of the Catholic Church, the devolution of health services to local government units, and the reproductive health framework and commitment made at the International Conference on Population and Development (ICPD) in Cairo in 1994 (Melgar et al., 2012). Moreover, external factors such as the gradual withdrawal of support of the United States government on the provision of contraceptive commodities also influenced the course of action taken by the government on the family planning program. The passage of Republic Act RA 10354, or the Responsible Parenthood and Reproductive Health Act (RPRH Law) in 2013, despite strong opposition from the Catholic Church, civil society, and other organizations, is considered a major achievement toward the provision of comprehensive reproductive health services and programs, including family planning (USAID, 2017).

Growth in contraceptive prevalence until 2030 is expected mainly in the regions of sub-Saharan Africa and Oceania. Between 2015 and 2030, the time period of the 2030 Agenda for Sustainable Development, contraceptive use is projected to grow particularly in regions where less than half of married or in-union women of reproductive age currently prevail. Contraceptive prevalence is projected to increase from 17 to $27 \%$ in Western Africa, from 23 to $34 \%$ in Middle Africa, from 40 to $55 \%$ in Eastern Africa, and from 39 to $45 \%$ in Melanesia, Micronesia and Polynesia. Yet unmet need for family planning is still projected to remain high till 2030 , above $20 \%$ in all these regions, except in Eastern Africa, where it is projected to decrease from $24 \%$ to $18 \%$ between 2015 and 2030 (United Nations, 2015).

Nearly 800 million married or in-union women are projected to be using contraception in 2030, and growth in the number of contraceptive users will be uneven across regions. The number of married or in-union women in the world, using contraception is projected to rise by 20 million, from 758 million in 2015 to 778 million in 2030. Growth in the number of contraceptive users is projected to be high for all regions of Africa and 
in Southern Asia. Globally, the number of women with an unmet need for family planning is projected to change little, from 142 million in 2015 to 143 million in 2030, due to growth in the number of married or in-union women of reproductive age in sub-Saharan Africa and growth in the demand for family planning (United Nations, 2015).

The number of women and girls using modern methods of contraception in the 69 FP2020 focus countries continues to rise by 2018 reaching more than 317 million. Core Indicator 1, the most direct measure of progress toward achieving the goal of additional 120 million modern users by 2020 , estimates that there are 46 million additional users of modern contraception compared to 2012 . This growth is approximately $30 \%$ greater than the normal trend. An increase in additional users of modern contraception implies that a country is not only maintaining its existing base of users, but is also attracting new or returning users. The number of additional users of modern methods can increase in two ways. One is through population growth, without a change in the proportion of women who choose to use contraception. As of 2018, there are 924 million women of reproductive age (15-49) in the 69 FP2020 focus countries, compared to 834 million in 2012: an increase of 90 million, or $11 \%$. Half of this population growth is from just five countries (India, Nigeria, Pakistan, Ethiopia, and Bangladesh). In these countries, just keeping up with population growth many more women are now using a modern method. The other way to increase additional users is through increasing the proportion of women who choose to use modern contraception; that is, increasing the contraceptive prevalence rate (Family Planning Summit, 2017).

The modern contraceptive prevalence rate (MCPR) among all women of reproductive age, indicates the proportion of women and girls using a modern method. There are significant regional variations in this indicator and the pace at which it moves. Although FP2020 focus countries are only a subset of the countries in each region, their patterns tend to reflect the larger regional picture. In FP2020 focus countries in Asia, 38\% of all women of reproductive age are using a modern method as of July 2018, and growth is just 0.2 percentage points per year. In contrast, the pace of MCPR growth in FP2020 focus countries in Africa has been much faster over the last several years. As of July 2018, 24\% of women of reproductive age in these countries are using a modern method; growth is $1.1 \%$ points per year in Eastern and Southern Africa and 0.7 percentage points per year in West Africa. Looking at progress from a country perspective provides additional insight into the variability of growth in contraceptive use (Family Planning Summit, 2017).

\section{CONCLUSION}

The study revealed that family planning counselling program is significant predictive variable for modern Contraceptive Prevalence Rate at 0.001 significance level. Thus, it can be concluded that it is highly necessary among clients to provide complete education and awareness regarding the different available modern methods of family planning in order to drive positive changes in behaviour and perceptions relating to contraceptive use especially on modern methods. The results would also strongly suggest that the status of modern Contraceptive Prevalence Rate from 2011-2018 significantly predict that the mCPR in 2022 will possibly reach the national objective of $30 \%$ from $24.9 \%$ in 2017.

Thus enhancement of the family planning counselling program should be given precedence to cater the health needs of the clients especially for the vulnerable populations (i.e. teenagers). Trained health care providers should always be available in any healthcare facilities especially in the primary level of services (i.e. Barangay Health Stations, Rural Health Units, and etc). Small and large group discussions should be constantly conducted in all areas of healthcare settings focusing on target clientele. Policies and development plans concerning family planning program should be reviewed by the Local Government Units with respect to the national and international objectives and standards. These standards must be then translated in the local level. Further research should be conducted to determine other determinants that possibly influence the use of modern contraceptive methods especially in geographically isolated and backward areas like the province of Lanao del Sur, Philippines.

\section{REFERENCES}

Almalik, M., Mosleh, S. \& Almasarweh, I. (2018). Are users of modern and traditional contraceptive methods in Jordan different? Eastern Mediterranean Health Journal, 24(4), pp 377-384.

Asian Scientist (2012). Philippine Government Struggles on Family Planning Debate. Retrieved from: 
https://www.asianscientist.com/2012/07/health/philippines-family-planning-program-contraceptives-catholicchurch-2012/

Cabato, R. (2017). Duterte orders full implementation of modern family planning by 2018. Retrieved from: http://nine.cnnphilippines.com/news/2017/01/11/Duterte-EO-supporting-family-planning.html.

Cleland, J., Conde-Agudelo, A., Peterson, H., Ross, J. \& Tsui, A. (2012). Contraception and health. Lancet, 380(9837), pp 149-56.

Creanga, A.A., Gillespie, D., Karklins, S. \& Tsui, A.O. (2011). Low use of contraception among poor women in Africa: an equity issue. Bulletin of the World Health Organization, 89(4), pp 258-66.

Dansereau, E., Schaefer, A., Hernández, B., Nelson, J., Palmisano, E., Ríos-Zertuche, D., Woldeab, A., Zúñiga, M.P., Iriarte, E.M., Mokdad, A.H. \& El Bcheraoui, C. (2017). Perceptions of and barriers to family planning services in the poorest regions of Chiapas, Mexico: a qualitative study of men, women, and adolescents. Reproductive Health, 14(1), 129.

Eltomy, E.M., Saboula, N.E. \& Hussein, A.A. (2013). Barriers affecting utilization of family planning services among rural Egyptian women. Eastern Mediterranean Health Journal, 19(5), pp 400-408.

Family Planning Summit (2017). Family Planning 2020: Measuring Progress. Retrieved from: http:// progress.familyplanning2020.org/content/measurement.

Geronimo, J.Y. (2016). Use of modern family planning methods in PH rose in 2015 - report. A report says government and non-governmental organizations allocated a total of P40.70 billion in 2015 for the implementation of the Reproductive Health law. Retrieved from: https:/www.rappler.com/nation/137256-2nd-report-implementationreproductive-health-rh-law-family-planning

Girija, N. \& S.K. Srivatsa (2006). A Research Study: Using Data Mining in Knowledge Base Business Strategies. Information Technology Journal, 5(3), pp 590-600.

GSS G. Ghana statistical service (GSS) (2009). Ghana health service (GHS), and ICF macro. Accra: Ghana Demographic and Health Survey 2009, pp 79-96.

Guttmacher Institute. Facts on Abortion in Asia (2012). Retrieved from: www.guttmacher.org

Handayani, L., Suharmiati, S., Hariastuti, I \& Latifah, C. (2012). Peningkatan Informasi tentang KB ; Hak Reproduksi yang Perlu Diperhatikan oleh Program Pelayanan Keluarga Berencana. Buletin Penelitian Sistem Kesehatan. 15(3), pp 289-297.

Jadloc, M.D. (2017). 1 in 3 Pinays use traditional over modern contraceptives. UP Diliman Information Office, University Theater, UP Diliman, Quezon City.

Kaydor, V.K., Adeoye, I.A., Olowolafe, T.A. \& Adekunle, A.O. (2018). Barriers to acceptance of post-partum family planning among women in Montserrado County, Liberia. Nigerian Postgraduate Medical Journal, 25(3), pp 143-148.

Kenton, W. (2019). Multiple Linear Regression - MLR Definition. Retrieved from: https://www.investopedia. com/terms $/ \mathrm{m} / \mathrm{mlr}$.asp.

Lauria, L., Donati, S., Spinelli, A., Bonciani, M. \& Grandolfo, M.E. (2014). The effect of contraceptive counselling in the pre and post-natal period on contraceptive use at three months after delivery among Italian and immigrant women. Annali dell'Istituto Superiore di Sanità, 50(1), pp 54-61.

Melgar, J.D., Melgar, A.R. \& Cabigon, J.V. (2012). "Family Planning in the Philippines." Zaman, W. et al. (Eds.). Family Planning in Asia and the Pacific: Addressing the Challenges. Selangor, Malaysia: International Council on Management of Population (ICOMP), pp 293-333.

Mirkin, B. (2019). Family Planning in the Philippines: Stalled Again. Inter Press service: News Agency. Retrieved 
from: http://www.ipsnews.net/2016/12/family-planning-in-the-philippines-stalled-again/.

Muanda, M.F., Ndongo, G.P., Messina, L.J. \& Bertrand, J.T. (2017). Barriers to modern contraceptive use in rural areas in DRC. Culture, Health \& Sexuality, 19(9), pp 1011-1023.

Mufdlilah, M., Aryekti, K., Johan, R.B. \& Purnamasari, D. (2017). Drop Out of Family Planning Acceptors Based on Contraceptive Methods in Rural and Urban Areas. International Journal of Sciences: Basic and Applied Research (IJSBAR), 36(7), pp 272-280.

Musdalifah, H. (2013). Faktor yang Berhubungan Dengan Droup out Pada Akseptor KB di Kecamatan Labakkang. Journal Stikes Nani Hasanuddin. Volume 3(4).

Najmi, H., Ahmed, H., Halepota, G.M., Fatima, R., U. Haq, M., Yaqoob, A., Latif, A., Ahmad, W. \& Khursheed, A. (2018). Community-based integrated approach to changing women's family planning behaviour in Pakistan, 2014-2016. Public Health Action, 8(2), pp 85-90.

Nansseu, J.R., Nchinda, E.C., Katte, J.C. \& Nchagnouot, FM5, Nguetsa GD6. (2015). Assessing the knowledge, attitude and practice of family planning among women living in the Mbouda health district, Cameroon. Reproductive Health, $12: 92$.

Okour, A.M., Saadeh, R.A. \& Zaqoul, M. (2018). Evaluation of Family Planning Counselling in North Jordan. Sultan Qaboos University Medical Journal, 17(4): e436-e443.

Philippine Statistics Authority (PSA) (2001). Contraceptive Use in the Philippines. Retrieved from: https://psa. gov.ph/content/contraceptive-use-philippines.

Philippine Statistics Authority (PSA) (2003). Use of Modern Methods up in Most Regions (Final Results from the 2002 Family Planning Survey). Retrieved from: https://psa.gov.ph/content/use-modern-methods-most-regions-finalresults-2002-family-planning-survey.

Philippine Statistics Authority (PSA) (2006). Contraceptive Prevalence Rate remains at 49 percent. Retrieved from: https://psa.gov.ph/content/contraceptive-prevalence-rate-remains-49-percent.

Philippine Statistics Authority (PSA) and ICF (2018). Key Findings from the Philippines National Demographic and Health Survey 2017. Quezon City, Philippines, and Rockville, Maryland, USA: PSA and ICF. Retrieved from: https://www.dhsprogram.com/pubs/pdf/SR253/SR253.pdf

Philippine Statistics Authority (PSA) and ICF International (2014). Philippines National Demographic and Health Survey 2013. Manila, Philippines, and Rockville, Maryland, USA: PSA and ICF International.

Polit, D.F. \& Beck, C.T. (2008) Nursing Research: Generating and Assessing Evidence for Nursing Practice. $8^{\text {th }}$ Edition, Wolters Kluwer Health/Lippincott Williams \& Wilkins, Philadelphia.

SEPO (2013). Contraceptive Use in the Philippines: At a glance. Retrieved from: https://www.senate.gov.ph/ publications/AAG\%20201304\%20\%200n\%20CPR\%20_Final.pdf.

Shrestha, A., Kayastha, B., Manandhar, S. \& Chawla, C.D. (2014). Acceptance of family planning amongst patients attending Dhulikhel hospital obstetrics and gynecology department. Kathmandu University Medical Journal (KUMJ), 12(47), pp 198-201.

Shumayla, S. \& Kapoor, S. (2016). Knowledge, attitude, and practice of family planning among Muslim women of North India. International Journal of Medical Science and Public Health, 26(5): PP 847-852.

United Nations (2015). Trends in Contraceptive Use Worldwide 2015. Retrieved from:https://www.un.org/en/ development/desa/population/publications/pdf/family/trendsContraceptiveUse2015Report.pdf.

US Department of Health and Human Services (2020). Healthy People 2020 Objectives: Family Planning. Washington, DC: Retrieved from: http://www.healthypeople.gov/2020/topicsobjectives2020/overview.aspx?topicid=13. 
USAID (2017). Ten Years of Traditional Contraceptive Method Use in the Philippines: Continuity and Change. Retrieved from: https://dhsprogram.com/pubs/pdf/WP130/WP130.pdf.

Westoff C.F. (2012). Unmet Need for Modern Contraceptive Methods. DHS Analytical Studies No. 28. Calverton, Maryland, USA: ICF International.

WHO (2018). Family planning/Contraception. Retrieved from: https:/www.who.int/news-room/fact-sheets/detail/familyplanning-contraception.

World Health Organization (WHO) (2011). Unsafe Abortion: Global and Regional Estimates of Incidence of Unsafe Abortion and Associated Mortality in 2008. $6^{\text {th }}$ edition. Geneva: WHO.

Yacobson (2018). Family Planning 101. Retrieved from: https://www.globalhealthlearning.org/course/family-planning-101 